\title{
Newly diagnosed primary hypothyroidism applicant with massive pericardial effusion and acute renal failure
}

\author{
Ates I, Kaplan M, Yilmaz N \\ Ankara Numune Education and Research Hospital, Department of Internal Medicine, Ankara, Turkey \\ E-mail:dr.ihsanates@hotmail.com
}

Objective. While non-symptomatic pericardial effusion is seen in primary hypothyroidism, massive pericardial effusion is a very rare finding. In the literature, newly diagnosed primary hypothyroidism cases presenting with massive pericardial effusion or acute renal failure are present, but we did not encounter any case first presenting with combination of two signs. In this case report, primary hypothyroidism case that presenting with massive pericardial effusion and acute renal failure will be discussed.

Subject and Results. Forty-eight years old male patient was hospitalized with shortness of breath, chest pain, swelling of the eyelids and bilateral limbs complaints. On chest radiograph heart shadow was deleted, pleural effusion was present until the middle zone of the left lung. Biochemical parameters (urea, creatinine, alanine aminotransferase aspartate aminotransferase, lactate dehydrogenase, sodium, potassium, creatine kinase, Troponin I, CK-MB, erythrocyte sedimentation rate, c-reactive protein) and thyroid stimulating hormone (TSH, $52.6 \mu \mathrm{g} / \mathrm{ml}$ ), free triiodothyronine $(\mathrm{T} 3,0.61 \mathrm{pg} / \mathrm{ml})$, free thyroxine $(\mathrm{T} 4,0.12 \mathrm{ng} / \mathrm{dl})$, anti thyroperoxydase $(343 \mathrm{IU} / \mathrm{ml})$, anti thyroglobulin $(1604 \mathrm{IU} / \mathrm{ml})$, were analyzed. The patient underwent pericardiocentesis. Levothyroxine treatment started with a dose of $0.05 \mathrm{mg}$ per day and increased gradually until the optimum dose provided. At the end of the third month, the values of TSH, free T4, and free T3 were measured $(2.3 \mu \mathrm{g} / \mathrm{ml}, 1.1 \mathrm{ng} / \mathrm{dl}, 2.54 \mathrm{pg} / \mathrm{ml}$, respectively). The patient recovered completely and pericardial effusion was not detected in echocardiography.

Conclusion. Massive PE and acute renal failure due to primary hypothyroidism is a rare clinical condition. Primary hypothyroidism should be kept in mind in patients with symptoms like shortness of breath, chest pain, and generalized edema; moreover, when acute renal failure and PE were detected. It should be considered that patient's biochemical parameters can improve starting from the two weeks after levothyroxine treatment started with pericardiocentesis in severe symptomatic patients.

Key words: acute renal failure, pericardial effusion, primary hypothyroidism

Corresponding author: Dr. Ihsan Ates, Ankara Numune Education and Research Hospital, Department of Internal Medicine, Sihhiye, Ankara, Turkey; phone: +90 312 5084666; fax: +90 31235690 03; e-mail: dr.ihsanates@hotmail.com. 
Pericardial effusion (PE) seen in patients with hypothyroidism is associated with the severity of the disease. While PE is commonly seen in patients with myxedema coma and severe hypothyroidism, it is very rare condition $(3-6 \%)$ in patients with moderate hypothyroidism (Patil et al. 2011). Primary hypothyroidism resulting with acute renal failure (ARF) (Sarnak et al. 2003) is a rarely diagnosed condition. Although co-existence of ARF due to rabdomyolysis and hypothyroidism is present in the literature, we did not encounter too many hypothyroidism cases associated with ARF of unknown cause. In this case report, primary hypothyroidism case presenting with massive PE and ARF association which have not seen previously in the literature, will be discussed.

\section{Subject and Results}

Forty-eight years old male patient was admitted to the polyclinic with shortness of breath, chest pain, swelling of the eyelids and bilateral limbs complaints. The patient's current clinical status began three weeks ago and gradually increased. Known alcohol, smoking and drug use and chronic disease history was not present. On physical examination, fever was $36.6^{\circ} \mathrm{C}$, pulse 52/min; blood pressure 160/95 $\mathrm{mm} \mathrm{Hg}$, respiratory rate $18 / \mathrm{min}$. Coarse hair, dry skin, bilateral periorbital edema, and neck vein distention were present. Heart sounds could be taken from deep and soft. In the lung, bilateral basillary fine crepitant rales predominantly on the left side were heard. Bilateral nonpitting lower extremity edema was present.

On laboratory tests, urea was $43 \mathrm{mg} / \mathrm{dl}(10-50)$, creatinine $2.3 \mathrm{mg} / \mathrm{dl}(0.5-1.2)$, alanine aminotransferase $28 \mathrm{IU} / 1$ (10-50), aspartate aminotransferase 79IU/1 (10-50), lactate dehydrogenase $886 \mathrm{U} / 1$ (240-480), sodium $131 \mathrm{mmol} / \mathrm{l}(136-145)$, potassium $4.9 \mathrm{mmol} / \mathrm{l}$ (3.5-5.1), creatine kinase $700 \mathrm{U} / 1 \quad(<190)$, Troponin

Table 1

Biochemical parameters by week

\begin{tabular}{lcccc}
\hline Parameter & Beginning & $\mathbf{4}^{\text {th }}$ week & $\mathbf{8}^{\text {th }}$ week & $\mathbf{1 2}^{\text {th }}$ week \\
\hline Sodium $(\mathrm{mmol} / \mathrm{l})$ & 131 & 134 & 137 & 138 \\
Potassium $(\mathrm{mmol} / \mathrm{l})$ & 4.90 & 4.70 & 4.10 & 4.20 \\
Urea $(\mathrm{mg} / \mathrm{dl})$ & 43 & 44 & 33 & 36 \\
Creatinin $(\mathrm{mg} / \mathrm{dl})$ & 2.30 & 2.00 & 1.30 & 0.90 \\
TSH $(\mu \mathrm{IU} / \mathrm{ml})$ & 52.60 & 41.30 & 24.40 & 2.30 \\
Free T4 $(\mathrm{ng} / \mathrm{dl})$ & 0.12 & 0.37 & 0.67 & 1.10 \\
\hline
\end{tabular}

Abbreviations: TSH - thyroid stimulating hormone;

free $\mathrm{T} 4$ - free thyroxine
I $0.021 \mathrm{ng} / \mathrm{ml}(0-0.15)$, CK-MB $8 \mathrm{U} / 1$ (7-25), erythrocyte sedimentation rate $27 \mathrm{~mm}(0-20)$, c-reactive protein $7.8 \mathrm{mg} / \mathrm{l}(0-5)$, thyroid stimulating hormone (TSH) $52.6 \mu \mathrm{g} / \mathrm{ml}$ (2.7-4.2), free triiodothyronine (T3) $0.61 \mathrm{pg} / \mathrm{ml}(2-4.4)$, free thyroxine (T4) $0.12 \mathrm{ng} / \mathrm{dl}$ (0.93-1.7), anti thyroperoxydase $343 \mathrm{IU} / \mathrm{ml}(<34)$, and anti thyroglobulin $1604 \mathrm{IU} / \mathrm{ml}(<115)$ (Table 1). On chest radiograph heart shadow was deleted, pleural effusion was present until the middle zone of the left lung (Figure 1). The electrocardiogram showed sinus rhythm with low voltage QRS complex and prolonged QT interval (0.42 s). Massive PE was found on echocardiography.

The patient underwent pericardiocentesis. Total $1900 \mathrm{ml}$ fluid was drained at two days. Pericardial fluid cytology and culture were not pathological. Levothyroxine treatment started with a dose of $0.05 \mathrm{mg}$ per day and increased gradually until the optimum dose provided. At the end of the third month, the values of $\mathrm{TSH}$, free T4, and free T3 were measured $(2.3 \mu \mathrm{g} / \mathrm{ml}$, $1.1 \mathrm{ng} / \mathrm{dl}, 2.54 \mathrm{pg} / \mathrm{ml}$, respectively) (Table 1). The patient recovered completely and pericardial effusion was not detected in echocardiography. To investi-

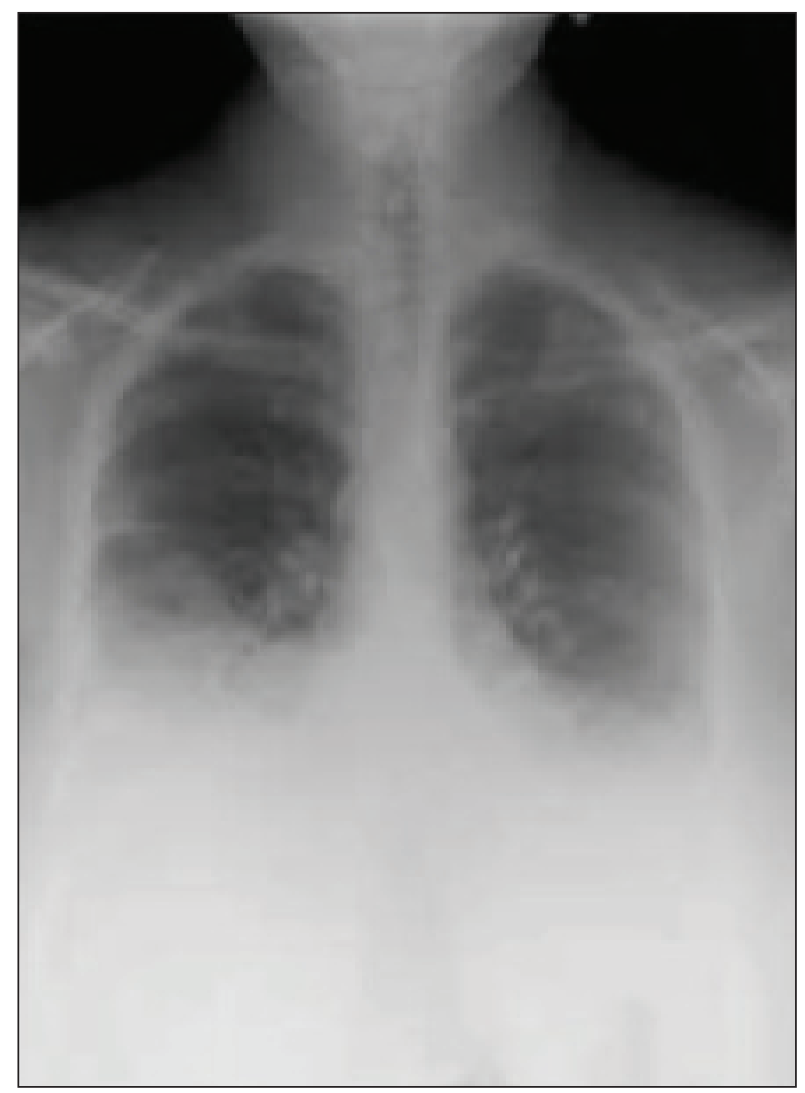

Figure 1. Bilateral pleural effusion in the chest radiography. 
gate the etiology of ARF, renal ultrasonography was done and kidneys revealed completely normal. After oral hydration, symptomatic treatment and levothyroxine, which was started after pericardial drainage, kidney tests returned completely to normal at the end of 12 weeks (Table 1 ).

\section{Discussion}

Co-existence of massive PE and ARF in primary hypothyroidism is a rarely encountered condition with high mortality. Although primary hypothyroidism cases presenting with massive PE (Thirone et al. 2012) or ARF (Rodrigo et al. 2011) are present in the literature, we did not encounter newly diagnosed primary hypothyroidism cases where both conditions together. If we take a look on the pathophysiology of PE in hypothyroidism, in prolonged stress situations such as hypothyroidism, pericardial pressure increases, pericardial volume usually expands and moves to the right (Little and Freeman 2006). Pericardial fluid begins to accumulate slowly, the pericardium tries to adapt this condition and pericardial pressure increases due to the parallel accumulation of fluid. Therefore, a large amount of fluid can accumulate in the pericardial space without any symptom.

Cardiac tamponade occurs when pericardial pressure equalizes first with right ventricle than left ventricle pressure. Although there was not a deep hypothyroidism in our patient, $1900 \mathrm{ml}$ fluid accumulation has been seen in a short time and patient became symptomatic. This condition may be due to different stress conditions associated with hypothyroidism. The pathogenesis of ARF development due to primary hypothyroidism has not yet been clearly understood. According to dominant conception, hypothyroidism causes plasma hypodynamic circulatory blood flow and reduction of glomerular filtration rate. This mechanism leads to pre-renal renal failure. Another reason of ARF is rabdomyolysis due to hypothyroidism and tubular damage with increased creatinine kinase (Rodrigo et al. 2011). ARF begins to improve 2 weeks after initiation of levothyroxine therapy as massive PE. In literature, majority of cases except one started to improve from the two weeks (Joshi et al. 2009). In our case, 2 weeks after pericardiocentesis, levothyroxine and oral hydration treatment renal function tests and electrolyte levels began to return to normal.

In conclusion, massive PE and acute renal failure due to primary hypothyroidism is a rare clinical condition. Primary hypothyroidism should be kept in mind in patients with symptoms like shortness of breath, chest pain, and generalized edema; moreover, when acute renal failure and PE were detected. It should be considered that patient's biochemical parameters can improve starting from two weeks after levothyroxine treatment started with pericardiocentesis in severe symptomatic patients.

\section{References}

Joshi B, Jones D, Rochford A, Giblin L. Hypothyroidism and associated acute renal failure. J R Soc Med 102, 199-200, 2009.

Little WC, Freeman GL. Pericardial disease. Circulation 113, 1622-1632, 2006.

Patil VC, Patil HV, Agrawal V, Patil S. Cardiac tamponade in a patient with primary hypothyroidism. Indian J Endocrinol Metab 15, S144-S146, 2011.

Rodrigo C, Gamakaranage CS, Epa DS, Gnanathasan A, Rajapakse S. Hypothyroidism causing paralytic ileus and acute kidney injury - case report. Thyroid Res 4, 7, 2011.

Sarnak MJ, Levey AS, Schoolwerth AC, Coresh J, Culleton B, Hamm LL, McCullough PA, Kasiske BL, Kelepouris E, Klag MJ, Parfrey P, Pfeffer M, Raij L, Spinosa DJ, Wilson PW, American Heart Association Councils on Kidney in Cardiovascular Disease HBPRCC, Epidemiology, Prevention. Kidney disease as a risk factor for development of cardiovascular disease: a statement from the American Heart Association Councils on Kidney in Cardiovascular Disease, High Blood Pressure Research, Clinical Cardiology, and Epidemiology and Prevention. Circulation 108, 2154-2169, 2003.

Thirone AC, Danieli RV, Ribeiro VM. [Massive pericardial effusion as initial manifestation of hypothyroidism]. Arq Bras Endocrinol Metabol 56, 383-387, 2012. 